\title{
PARADIGMAS INOVADORES EM PLANEJAMENTO URBANO E GESTÃO*
}

\author{
BEATRIZ FLEURY E SILVA ${ }^{1}$ \\ LUIZ ANTÔNIO N. FALCOSKI ${ }^{2}$
}

SILVA, B. F. e; FALCOSKI, L. A. N. Paradigmas inovadores em planejamento urbano e gestão Semina: Ci. Exatas/Tecnol. Londrina, v. 21, n. 4, p. 77-82, dez. 2000.

\begin{abstract}
RESUMO: O presente artigo discute a necessária revisão do processo do planejamento e políticas públicas, no alcance a um maior conhecimento e definição de estratégias de controle urbano, podendo tratar os conflitos decorrentes da produção da cidade e antecipar as relações e reações do sistema urbano. Deste modo, será apresentada algumas iniciativas municipais, que abordam novas metodologias de investigação, contemplando processos democráticos de planejamento e gestão urbana.
\end{abstract}

PALAVRAS-CHAVE: Planejamento urbano, gestão urbana, políticas públicas, revisão metodológica.

\section{INTRODUÇÃO}

A atuação do planejamento urbano nas cidades brasileiras, tem se limitado a decisões isoladas, fragmentadas, desatualizadas e por consequência, se utilizando de instrumentos incapazes de tratar o processo de produção e uso do espaço como resultado de interfaces de um mesmo contexto sócio-espacial e ambiental.

Há uma necessidade de tratar os conflitos sociais decorrentes da produção e uso do espaço da cidade e de antecipar as relações e reações do sistema urbano frente a qualquer estímulo, para melhor provê-lo de infra-estruturas, serviços e equipamentos urbanos. Estes conflitos resultam de atividade cotidiana e necessitam, assim, de mecanismos e instrumentos compatíveis com esta dinâmica, o que torna evidente um processo de realimentação periódica de informações urbanas para possibilitar decisões mais rápidas, tratando com simultaneidade os problemas urbanos.

Esta necessária revisão, caminha para a utilização de métodos de avaliação sob a forma de indicadores urbanos e não mais sob a forma de dados simplificados sobre a cidade. Trabalhar com indicadores que contenham uma resposta de qualidade urbana, capazes de antecipar as reações cotidianas do sistema urbano frente a qualquer estímulo, possibilitando assim a previsão de impactos, simulação de cenários e assim, auxiliar na construção de desempenhos desejáveis.

Neste sentido, pretende-se discutir novos instrumentos de renovação urbanística, através da incorporação cada vez mais crescente por parte de iniciativas municipais, de novos processos e instrumentos informatizados e democráticos de planejamento e gestão urbana.

1 POR UMA RENOVAÇÃO NO PROCESSO DE PLANEJAMENTO E GESTÃO URBANA

O planejamento urbano hoje é uma prética em crise, não assegurando o controle das transformações urbanas cada vez mais complexas, havendo necessidade de se rever não só suas ações, mas seus instrumentos e principalmente o modelo de cidade que temos hoje.

Rolnik (1997), adverte que o modelo de cidade que trabalhamos metodologicamente é baseado na cidade ideal, que se confronta com a cidade real, uma vez que este modelo não leva em consideração a cidade como palco de conflito pela apropriação do solo e pelas oportunidade econômicas, além disso não temos um instrumento de medição deste conflitos. Defende um modelo urbanístico heterogêneo e pluridimensional, baseado na noção de cidades míltiplas, que contém o lado formal

* Este artigo foi desenvolvido a partir da dissertação de mestrado em Engenharia Urbana - UFSCar, defendida pela autora em 2000, intitulada - SIAD - Sistemas de indicadores de Avaliação de Desempenho Urbano e Ambiental.

1 Arquiteta, Mestre em Engenharia Urbana, Professora da UEL, Campus Universitário, Caixa postal 6001 - CEP $86051-990$ Londrina - PR. Tel. (43) 322 5422. e-mail: <bfsilva@uel.br>.

2 Arquiteto, Doutor em Arquitetura, Professor da UFSCar Via Washington Luís, km 235 - Caixa postal 676 - CEP $13565-905$ - São Carlos - SP. Tel. (16) 260 8292. e-mail: <falcoski@power.ufscar.br>. 
(legal) e informal (parcela da cidade de formação ilegal).

O modo como vimos regulando estas disparidades (ideal $x$ real), não passa em nenhum momento por um guia estratégico e de prioridades para a cidade, uma vez que não estabelece mecanismos de gestão democrática, através do qual pode-se chegar a uma relação mais próxima com interesses reais.

As operações de planejamento devem possibilitar decisões políticas tomadas pelas ações de desenvolvimento de cada cidade. Planos mais estratégicos e menos pré-deterrminados, formulando propostas para setores considerados prioritários e que mudam de cidade para cidade. Devem também ser mais integradores, identificando áreas de intervenção, estabelecendo urn zoneamento políticos programado de ação e mais desenhados, pois a forma urbana não pode ser reduzida a soma de intervenções isoladas, mas sim resultados de uma estrutura de continuidade, além de resultar em um processo democrático de gestão urbana.

Rolnik salienta também, que o planejamento urbano deve considerar dois enfoques indissociáveis: - equilíbrio sócio-ambiental e a justiça sócioambiental, dentro de um modelo urbanístico inovador, democrático, expressando um nova ordem ética e estético-simbólica, baseado na co-responsabilidade, na retomada do espaço público e essencialmente no renascimento da dimensão pública da cidade para todos.

Atualmente, o que vemos são administrações municipais que não estão correspondendo as questões colocadas como fundamentais para qualificação dos espaços urbanos e sua composição como espaço social da cidade. O descaso e a ausência de políticas púbiicas no tratamento destes espaços, é um indicativo do descompasso entre crescimento real da forma urbarna e os instrumentos utilizados para intervenção desta realidade.
Complementando a discussão anterior, a contribuição de Portas (1993) vem de encontro com a renovação do planejamento urbano, tratando dos novos paradigmas existentes hoje sobre o assunto:

Hoje o urbanismo é altamente negocial. [...] O Plano não é mais o território onde tudo estava previsto e tinha lugar. O Plano é cada vez mais um conjunto de lugares disponiveis para aquilo que se venha a discutir mais tarde. O Plano não é mais para ser feito e cumprido, mas para interpretado. É menos partitura antiga e mais jazz session. [...] Há certos aspectos estruturais consensuais, que deve manter sua rigidez e outros que vão ser interpretados de maneira diforente.

Sefaz portanto oportuno, inserir novas abordagens na investigação do espaço urbano e sua gestão, avançando em discussões que proponham uma renovação conceitual, metodológica e instrumental de alcance aos processos dinâmicos e de transformação da estrutura urbana da cidade.

Outra abordagem que deve ser referenciada é a convergência transdiciplinar de estudo e produção de normas prescritivas, dentro de uma revisão e requalificação urbanística, enquanto campo disciplinar e cognitivo do conhecimento. Contribuições de ordem teórico-conceitual e metodológica apontam para uma nova integração conceitual das ciências do território, envolvendo novas abordagens de urbanismo, geografia urbana, ecologia, engenharia urbana, ambiental, gerenciamento urbano e desenho urbano. Esta revisão disciplinar permite requalificar o conceito "espaço físico" para "espaço e desenho ambiental".

Paralelamente a todas estas novas conceituações e pesquisas surgem campos disciplinares e profissionais, integrados a novos instrumentos de representação e análise espacial e territorial. 
Quadro 1 - Novos campos disciplinares e profissionais na requalificação do processo de planejamento. Fonte: Falcoski (1997), com adaptações de Silva (1998).

ENGENHARIA URBANA, PLANEJAMENTO, URBANISMO E GESTÃO TERRITORIAL

- Novos instrumentos tecnológicos e operacionais de sistemas urbanos de infra-estrutura

- Diretrizes prescritivas de desempenho urbano e qualidade ambiental

- Novas categorias analíticas, análise morfológica e impacto ambiental entre forma

urbana/desenho urbano e subsistemas de infra-estrutura

- Relações de desempenho entre sistemas de movimento-transporte e estruturas urbanas

- Novos instrumentos técnicos-jurídicos-normativos

]$[5$

- Novos processo de base cadastral informatizada, sistemas de informaçöes espacial e banco de dados digitais georreferenciadas em CAD-GIS

- Facilidade de sistematização de um conjunto complexo de dados disponíveis sobre usos do solo e problemas ambientais urbanos

- Orientação e monitoramento de processos de intervenção e transformação urbana

1.1 Instrumentos Inovadores de Planejamento Urbano e Novas Territorialidades

As transformações urbanas vividas no País, desencadeiam preocupações de dois níveis: é preciso medir os conflitos sociais decorrentes da produção do espaço e prever as reações do sistema urbano frente a quaisquer estímulos. Como estes conflitos são decorrentes de atividades contínuas, os instrumentos também devem ser desta natureza assim como o território urbano, que precisa ser tratado sob nova representação espacial para se conhecer e atuar de acordo com suas particularidades.

Os instrumentos inovadores de planejamento urbano tem acompanhado novas tendências de territorialização-representação espacial, planejando, gerenciando e monitorando o desenvolvimento da estrutura urbana através da divisão territorial/ macrozoneamento do solo urbano, configurandose como um processo de suporte a decisão na busca de maior domínio destes conflitos acima.

Juntamente com estas novas territorialidades, tern sido cada vez mais presente nas experiências municipals uma leitura da cidade sob a ótica de indicadores urbanos, possibilitando maior entendimento e medição dos impactos advindos do sistema urbano e não mais se utilizando de dados simplificados e acabados sobre determinada área ou tema.

É importante ressaltar que o uso que se faz destes indicadores urbanos presentes nas experiências municipais nacionais acontece no sentido de poder antecipar, reconhecer, medir e interpretar problemas urbanos, auxiliar na análise de desempenhos, tendências e impactos de determinadas políticas, sendo que estes indicadores devem ser utilizados considerando alguns critérios como:

- Possuir relevância para as propostas urbanas;

- Ser de fácil compreensão, capazes de suprir um amplo entendimento da saúde ambiental, econômica e social da cidade;

- Medíveis, capazes de mostrar a magnitude do problemas;

- Confiáveis, devendo possuir demonstração convincente, que objetivos estão sendo encontrados;

- Flexíveis devendo se alterar a medida que houver necessidade; 
- Sem ambiguidade, devendo possuir claras definições e objetivos;

- Independentes, possuir um indicador para cada objetivo;

- Devem ser aplicados considerando a análise em tempos distintos: curto, médio e longo.

Portanto, devem possuir os indicadores uma caracterização multivariável, instrumentos essenciais de planejamento urbano e gestão, considerados mais do que um produto, um processo, explicitando o comportamento do sistema urbano e direcionando medidas de planejamento, diagnósticos, avaliações de desempenho configuracional e processos de gestão urbana.

Alguns exemplos referenciais tanto de propostas territoriais de gestão, quanto utilização de indicadores urbanos como ferramenta no processo de planejamento, encontram-se no Plano Diretor de Desenvolvimento Urbano e Ambiental de Porto Alegre-RS - $2^{\circ}$ PDDUA, no Programa de Indicadores Urbanos e Habitacionais-Monitoramento de Assentamentos Humanos da Prefeitura de Recife, no Índice de Qualidade de Vida Urbana de Belo Horizonte - IQVU e nos Projetos de Estruturação Urbana do Rio de Janeiro - PEUS.

\subsubsection{A Experiência de Porto Alegre - $2^{\circ}$ PDDUA}

A Administração Municipal de Porto Alegre, através da Secretaria de Planejamento Municipal, aprovou $02^{\circ}$ PDDUA - Plano Diretor de Desenvolvimento Urbano Ambiental, ficando apenas para ser aprovado alguns elementos de ordem operacional, ainda em discussão.

O $2^{\circ}$ PDDUA, trata a cidade de Porto Alegre de forma global, incorporando as áreas informais a chamada cidade formal. Reconhece as diferentes cidades que existem dentro da cidade, tracando diretrizes para o desenvolvimento equilibrado de cada uma delas, dentro de um conceito de cidade "sustentável", destacando o que de melhor existe em cada uma de suas regiões, buscando potencializá-las.

De maneira geral o $2^{\circ}$ PDDUA compõe-se de sete estratégias básicas: estratégia de Estruturação Urbana; estratégia de Mobilidade Urbana; estratégia de Uso do Solo Privado; estratégia de Qualificação Ambiental; estratégia de Produção Econômica; estratégia da Produção da Cidade; sistema de Gestão e de Planejamento.

Diante destas diretrizes, foi elaborado um Modelo Espacial, que por suas características de ocupação do solo, dinâmica e fluxos urbanos, merecem tratamento especial quanto aos modos de desenvolvimento e controle de crescimento, incorporando a cidade consolidada de ocupação intensiva e a cidade de ocupação rarefeita.

Em seu Modelo Espacial, o Município de Porto Alegre divide-se em Áreas de Ocupação Intensiva e Áreas de Ocupação Rarefeita. Estas áreas dividem-se em Unidades de Estruturação Urbana, Macrozonas e Regiões de Planejamento unidades de divisão territorial para fins de descentralização da gestão participativa do desenvolvimento urbano ambiental.

Outro aspecto inovador do $2^{\circ}$ PDDUA pertencente ao Sistema de Planejamento, que tem como objetivo articular as políticas públicas com as demandas da sociedade, é a criação do Sistema de Avaliação de Desempenho Urbano-SADU, proposto como um instrumento de suporte a decisão das avaliações de implantação de atividades especiais, empreendimentos de impacto, monitoramento de desenvolvimento urbano e elaboração de estudos com vistas à predição de situações

Diante da criação de um Modelo Espacial e do Sistema de Planejamento, abrem-se caminhos para a reestruturação das práticas de planejamento com novos instrumentos de gestão, garantindo um gerenciamento mais eficaz direcionado ao desenvolvimento sustentável e, consequentemente melhoria da qualidade de vida.

1.1.2 A Experiência de Recife - Programa de Indicadores Urbanos e Habitacionais

Vinculado a Secretaria de Planejamento do Estado e que integra o Sistema Gestor Metropolitano, atendendo ao desdobramento regional da Estratégia de Desenvolvimento Sustentável para o Estado de Pernambuco até ano 2010, encontra-se o Programa de Indicadores Urbanos e Habitacionais de Recife. Seu princípio metodológico se baseia no planejamento participativo e constitui experiência ímpar no processo de planejamento metropolitano, envolvendo em sua elaboração técnicos, universidade, especialistas e organizações governamentais.

O Plano trabalha com a perspectiva da metrópole desejada, objetivos, diretrizes, estratégias de ação e modelo de gestão, ou seja, introdução de novos processos de gestão que estejam sendo tratados com base no planejamento estratégico, flexível de acordo com uma leitura da cidade ou região que se quer ter.

O Programa constitui-se em um documento de natureza estatística elaborado pelo Departamento de Informações e Projeções da Secretaria de Planejamento Urbano e Ambiental (SEPLAM) da Prefeitura da Cidade de Recife, para atender 
solicitação da Secretaria de Política Urbana do Ministério do Planejamento e Orçamento como contribuição para a Conferência das Nações Unidas sobre Assentamento Humanos (Habitat II), ocorrida em 1996, em Istambul.

O Programa foi elaborado em dez módulosrelativos aos aspectos: Urbanos, Transportes, Controle Ambiental, Governo Local e Habitação da cidade de Recife.

Dentro desta perspectiva, a cidade foi dividida em regiões político-administrativas, microrregiões e bairros.

O sistema de obtenção das informações pode ser feito via Internet, através de consulta de ambiente interativo-imagens gráficas e banco de dados, onde o usuário indica a região de interesse relacionada em um mapa da cidade que surge na tela ou procura pela letra inicial do bairro, que consta abaixo do mapa. De acordo com o módulo selecionado, existe uma lista de informações bairro a bairro.

1.1.3 A Experiência de Rio de Janeiro-Projetos de Estruturação Urbana

Outra experiência interessante, instituída em 1992, é o Plano Diretor Decenal da Cidade do Rio de Janeiro, que embora com críticas e polêmicas em relação à sua tramitação e aprovação, está fundamentado em um modelo espacial através dos Projetos de Estruturação Urbana-PEUS. O plano prevê uma revisão dos modelos urbanos vigentes com propostas de tratamento das especificidades e potencialidades de cada área. Se constituem em alternativas para adequar o conjunto de leis urbanísticas e edilícias à dinâmica das áreas e suas transformações ao longo dos anos, além de incorporar a participação dos moradores nas discussões, promovendo gestão democrática, participativa, que trabalha cada setor da cidade com detalhada atenção para suas transformações.

1.1.4 A Experiência de Belo Horizonte - índice de Qualidade de Vida Urbana

A Secretaria Municipal de Planejamento de Belo Horizonte-MG, assessorada pela Pontífice Universidade Católica de Minas Gerais - PUC, propôs um modelo de gestão urbanístico, para avaliar a qualidade ambiental de fragmentos urbanos e monitorar os impactos das ações e intervenções públicas, denominado índice de Qualidade de Vida Urbana-IQVU, previsto no Plano Diretor do Município de Belo Horizonte.

A proposta é avaliar a qualidade de vida de um lugar, considerando a distribuição diferencial de serviços e recursos humanos públicos e privados, e a acessibilidade da população local. Consiste na elaboração de indicadores de qualidade e quantidade da oferta de determinados serviços, através de informações georeferenciadas em unidades espaciais da cidade estruturadas em índices locais e setoriais integrados e que configuram o IQVU de cada unidade espacial.

O IQVU representa uma inovação quanto aos índices tradicionais, pois além de medir a oferta localizada, mede o quanto esta oferta é compartilhada na cidade. Este índice, como característica peculiar de informação georreferenciada, possibilita monitorar e avaliar permanentemente o processo de expansão urbana, não só indicando demanda dos serviços e os resultados da ação pública, como a avaliação e simulação das intervenções sobre o sistema viário e transporte coletivo.

Este índice foi elaborado a partir da estruturação de 81 unidades espaciais de planejamento - UP, que foram definidas considerando alguns critérios para a definição do contorno das Regiões Administrativas de Belo Horizonte, grandes barreiras físicas naturais ou construídas, continuidade de ocupação e padrão de ocupação. Assim foram definidas as unidades espaciais (recortes do espaço urbano) em unidades com relativa homogeneidade para efeito de comparações. As favelas (exceto as menores que foram incorporadas às UP próximas) e os conjuntos habitacionais foram considerados independentes destas unidades.

O IQVU apresenta-se como instrumento de medição de condições de vida nos locais intraurbanos de Belo Horizonte no momento de sua aplicação e assim, priorizar os recursos de forma objetiva, e monitorar o plano diretor identificando possíveis erros nos parâmetros e ações urbanísticas implementadas. Constitui-se assim, além de um sistema cadastral de informação, com uma estrutura organizacional e operacional de variáveis e atributos que geram índices que podem estar constantemente sendo visualizados por qualquer tipo de usuário, um instrumento de suporte à decisão levando uma gestão a adquirir caráter interativo.

\section{CONSIDERAÇÕES FINAIS}

Acredita-se que com estes exemplos, se tenha ilustrado as recentes tendências de se planejar e gerir a cidade, indicando uma renovação na tomada de decisões das políticas públicas, por meio de metodologias e instrumentos que permitem gerenciar e monitorar continuamente as diversas ações dos agentes sociais. 
Deverá ser visto na perspectiva de uma reforma urbana (que contemple a participação, a ação comunicativa e a consulta interativa dos diversos agentes sociais)e administrativa municipal, resgatando a credibilidade do processo técnicopolítico da gestão do planejamento e de seu instrumental normativo, em substituição ao planejamento técnico-tradicional.

SILVA, B. F. e; FALCOSKI, L.A.N. Innovating paradigms in urban planning and management. Semina: Ci. Exatas/Tecnol. Londrina, v. 21, n. 4, p. 77-82, dez. 2000.

ABSTRACT: This article presents a discussion on the necessary review of the planning and public policies process, in order to reach knowledge and definition of urban control strategies. It will also deal with the conflicts deriving from the city formation and anticipate the relations and reactions of the urban system. Thus, some municipal initiatives will be presented. New investigation ethodologies will be broached, including democratic planning and urban management processes.

KEY WORDS: urban planning; urban management; public policies; methodological review.

\section{REFERÊNCIAS BIBLIOGRÁFICAS}

PORTAS, Nuno. Tendências do Urbanismo na Europa. Revista Oculum, Recife, n. 3, p. 4-13, 1993.

PORTO ALEGRE. Prefeitura Municipal. Secretaria de Planejamento. Plano Diretor de Desenvolvimento Urbano e Ambiental - $2^{\circ}$ PDDUA. Disponivel em: <httpll www.portoalegre.rs.gov.br>. Acesso em: 1996.

RECIFE. Preteitura Municipal. Secretaria de Planejamento Urbano e Ambiental. Programa de indicadores Urbanos e Habilacionais - Monitoramento de Assentamentos Humanos. Disponivel em: <http//www.emprel.gov.br>. Acesso em: 1994.

ROLNIK, Raquel. Políticas Públicas, Planejamento Estratégico e Gestão Urbana. In: FALCOSKI, L. A. (Org.). Seminário São Carlos - Projoto Urgente, 1997, São Carlos. Anais. São Carlos: UFSCar, 1997. p.22-26.
Planejamento Urbano nos Anos 90. Novas Perspectivas para Velhos Temas. In: RIBEIRO, Luiz César Queiroz (Org.). Globalização, Fragmentaçāo o Reforma Urbana. Rio de Janeiro: Civilizaçăo Brasileira, 1995.

SILVA, Beatriz Fleury $\theta$. SIAD - Sistemas de Indicadores de Avaliação de Desempenho Urbano e Ambiental. 2000. Dissertação (Mestrado em Engenharia Urbana) - Un versidado Federal de Säo Carlos (UFSCar), Departamento de Engenharia Civil, São Carlos, 2000.

SOUZA, Patrus Ananias. IQVU - Indice de Qualidade de Vida Urbana. Secretaria Municipal de Planejamento. Prefeitura Municipal de Belo Horizonte. Publicação Assessoria de Comunicação Social. 